\title{
ENVIRONMENTAL EXPOSURES TO LOW LEVEL OF CADMIUM AND LEAD AND HEARING IMPAIRMENT IN IRAQI PATIENTS
}

\author{
WROOD S AL-KHFAJY ${ }^{1 *}$, GHADEER KADHUM BAIEE ${ }^{2}$, INAM SAMEH ARIF ${ }^{1}$ \\ ${ }^{1}$ Department of Pharmacology and Toxicology, College of Pharmacy, Mustansiriyah University, Baghdad, Iraq. ${ }^{2}$ Babel Health Directorate, \\ Forensic division, Drugs and Poison Unit, Iraq. Email: pharm.wroodsalim@uomustansiriyah.edu.iq
}

Received: 26 March 2017, Revised and Accepted: 24 May 2018

\section{ABSTRACT}

Objectives: We examined the relations between blood cadmium and lead exposure and hearing impairments in the Iraqi people.

Methods: We analyzed data from 51 individual 13-75 ages who had been randomly dispensed to the audiometry examination center at Al-Hilla Teaching Hospital (Babel) for each Iraqi civilian who said, "I suffering from the hearing problem." Pure-tone average (PTA) of auditory thresholds at frequencies of $0.5,1,2$, and $4 \mathrm{kHz}$ was calculated, and hearing impairment was described as a PTA $>25 \mathrm{~dB}$ in either ear.

Results: All patients who suffer from hearing impairment have serum lead level (23.14 $\pm 1.76 \mu \mathrm{g} / \mathrm{dL})$, which is a significantly elevated in comparison to control group $(21.20 \pm 2.08 \mu \mathrm{g} / \mathrm{dL})$. In addition to lead, the blood level of cadmium in people with hearing impairment was showed a significant elevation $(0.28 \pm 0.05 \mu \mathrm{g} / \mathrm{dL})$ in comparison to normal people $(0.22 \pm 0.03 \mu \mathrm{g} / \mathrm{dL})$. In general, this elevation remains within normal reference for the blood level of cadmium $(0.5 \mu \mathrm{g} / \mathrm{dL})$.

Conclusions: The present study revealed that the environmental and occupational cadmium and lead coexposures lead to a significant elevation in the blood level of these metals and could have an essential part in the progression of hearing loss.

Keywords: Cadmium, Hearing loss, Lead, Environmental toxicology, Pure-tone audiometry.

(C) 2018 The Authors. Published by Innovare Academic Sciences Pvt Ltd. This is an open access article under the CC BY license (http://creativecommons. org/licenses/by/4. 0/) DOI: http://dx.doi.org/10.22159/ajpcr.2018.v11i7.26235

\section{INTRODUCTION}

Overexposure to heavy metals can cause multi-adverse clinical disorders, which selectively disturb the function of a different of organs and cells in the human body. In general, their toxicity is independent of the source of exposure but highly dependent on the dose and duration of exposure that affects the overall accumulation of the metal in the body [1]. Consistently, it has been reported that low in addition to high exposure levels to heavy metals have resulted in significant various toxic responses such as cardiotoxicity, pulmonary toxicity, and hepatotoxicity [2].

Hearing impairment is one of the most widespread chronic disorders affecting elder adults with the impact on functional physical disability [3]. According to the World Health Organization (WHO): In 2018, about 466 million individuals worldwide have the disabling hearing impairment and about $7 \%$ of these are children. Prospectively, it is expected that by 2050 , above 900 million people would have disabling hearing loss [4]. Hearing loss can disturb communication and can, therefore, lead to a perceived reduction in all aspect of life and economic development. In adolescents, even minor hearing impairment can cause learning challenges related to communication difficulties and potentially result in lower academic achievement [5]. There are many studies suggest that exposure to environmental and occupational substances could affect the hearing system and result in audiometry dysfunctions [6].

Furthermore, exposure to some of the heavy metals for a long time is able to result in severe hearing ototoxicity [7]. There is a growing body of experimental evidence, suggesting that lead and cadmium may have some reducing effect on hearing function. The possible underlying mechanisms involved in their ototoxic effects is the excessive depletion of glutathione, and protein-bound sulfhydryl groups result from oxidative stress of these metals, which dramatically have been implicated in declining in blood flow and lipid peroxidation in the cochlea, leading to latency in conduction of the auditory nerve with subsequent elevation of physiological hearing thresholds $[7,8]$.

Most environmental contamination and human exposure have been resulting mostly from anthropogenic activity such as mining processes and home consuming of metals and metal-comprising compounds [9-11]. According to 2015 data, the Institute for Health Metrics and Evaluation has estimated that lead exposure expected for 494-550 victims and loss of 9.3 million disability-adjusted life years due to long-term impact on healthiness. Relatively, the maximum risks are in the countries that rated as low-medium income [12]. Promisingly, the successful declining down of leaded gasoline in many countries, besides with other lead control agencies, has resulted in a significant decrease in serum lead concentration in people. Recently, just three countries around the world are still using the lead-mixed petroleum, and unfortunately, Iraq is one of them [13].

Although high exposure to heavy metals in occupational sites and auditory impairment has been studied, slight is known about the ototoxic effects of long-term exposure to low-level metals in the general population. With respect to lead and cadmium, a few studies of low blood level and hearing impairment have been investigated [14-18].

While risk to lead and cadmium has decreased largely in many countries, these heavy metals continue to be widely used in a variety of consumer products, and environmental exposure to heavy metals is known to be particularly high in Iraqi cities where bombing, military events, and waste incineration have led to increased public exposures [19]. However, no epidemiologic studies have studied the association between environmental exposures to heavy metals and hearing impairment in the Iraqi people. Therefore, the purpose of this work was to examine the association between environmental exposures to lead and cadmium and the risk of hearing impairment in Iraqi people. 


\section{METHODS}

\section{Study population}

This study was done in Al-Hilla Teaching Hospital (Babel) in the audiology unit for Iraqi civilian who said, "I suffering from the hearing problem." We took 51 patients complaining from hearing problems; their ages were ranging from 13 to 75 years old; and we measured PTA for each person. We divide our patients into 2 groups:

- Group 1:10 patients have normal PTA $(\mathrm{n}=10)$ consider as the control group.

- Group 2: 14 patients with neurosensory hearing impairment (moderate-severe) $(\mathrm{n}=14)$.

The remaining patients (27 patients) with conductive or mixed hearing losses excluded from this study

\section{Audiology testing}

Audiometry analysis was accomplished in a special room isolated from sound, and this procedure is done by health technicians qualified by the National Institute for Occupational Safety and Health licensed as an audiologist who using an audiometer (Interacoustics Model AD226) with standard headphones (TDH-39) and insert earphones (Etymotic Ear Tone 3A). Pure-tone air-conduction hearing thresholds were examined for each ear at frequencies from 0.5 to $8 \mathrm{kHz}$. We calculated as a pure-tone average (PTA) hearing thresholds (dB) at speech frequencies $(0.5,1,2$, and $4 \mathrm{kHz})$ and as a PTA (high PTA) hearing thresholds at high frequencies $(3,4$, and $6 \mathrm{kHz})$ [20]. Consistent with the description used by the $\mathrm{WHO}$, hearing impairment was termed as a PTA $\geq 25 \mathrm{~dB}$ in any ear [21].

\section{Determination of blood lead level}

Trichloroacetic acid (TCA) $2.5 \mathrm{~mL}$ was added to $2.5 \mathrm{~mL}$ of whole blood and $0.1 \mathrm{~mL}$ of TCA was added to $1.0 \mathrm{~mL}$ of seminal plasma (1:1) to precipitate proteins, mixed well with wooden stick and centrifuged at $3000 \mathrm{rpm}$ for $10 \mathrm{~min}$ to remove cellular debris, and the supernatant was transferred to a clean plain tube and aspirated directly into the flame [22].

\section{Determination of serum cadmium level}

Blood samples for cadmium measurements were drawn into trace metal-free ethylene diamine tetra acetic acid tubes, and specimens were immediately transferred at $2-8^{\circ} \mathrm{C}$ to a central laboratory of $\mathrm{Al}-$ Hillah teaching hospital for analysis. Samples were transported in a portable cooler to toxicology center in the Laboratory of Poisoning Consultation Centre in the Medical City for measuring lead and cadmium concentrations in venous whole blood using atomic absorption device (Model: Buck 210VGP, USA) for each sample. The limits of detection were $0: 12 \mu \mathrm{g}=\mathrm{dL}$ and 0:056 $\mu \mathrm{g}=\mathrm{L}$ for blood lead and cadmium, respectively.

\section{Statistical analysis}

The outcomes were expressed as mean $\pm \mathrm{SD}$. Unpaired student $t$-test was used to examine the difference in the mean of test parameters, where $\mathrm{p}<0.05$ was considered statistically significant.

\section{RESULTS}

\section{Lead serum level}

After sample collection and the measurement of some serum heavy metal, this study found that patients who suffering from hearing impairment have serum lead level $(23.14 \pm 1.76 \mu \mathrm{g} / \mathrm{dL})$ a significantly elevated in compare to control group $(21.20 \pm 2.08 \mu \mathrm{g} / \mathrm{dL}$ ) (Fig. 1 and Table 1).

\section{Cadmium blood level}

In addition to lead, the blood level of cadmium in people with hearing impairment was showed a significant elevation in compare to normal people (control group). In general, this elevation remains within normal reference for blood level of cadmium (0.5 $\mu \mathrm{g} \mathrm{g/dL})$ (Fig. 2 and Table 2).

\section{DISCUSSION}

This is the first study of relations between heavy metals and hearing impairment evaluated simultaneously in Iraqi people. In our investigation of the illustrative sample of Al-Hilla city adults and adolescents who contributed to this study, higher exposure to lead and cadmium was significantly associated with high-frequency hearing impairment. The high occurrence of hearing impairments increases in humans who reside in manufacturing sites. The permanent impairment of hearing is a typical consequence of most heavy metals [23].

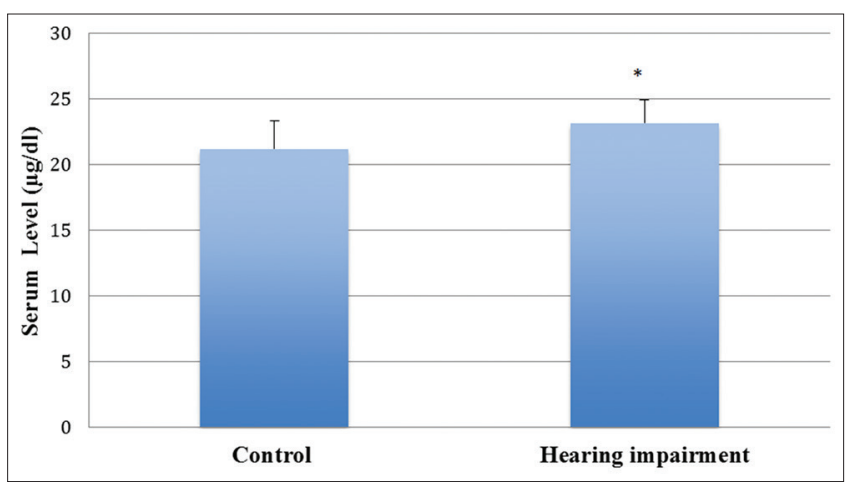

Fig. 1: Serum lead level in the normal people and people with hearing impairment. *Mean significant changes in compare to control group $(\mathrm{p}<0.05)$

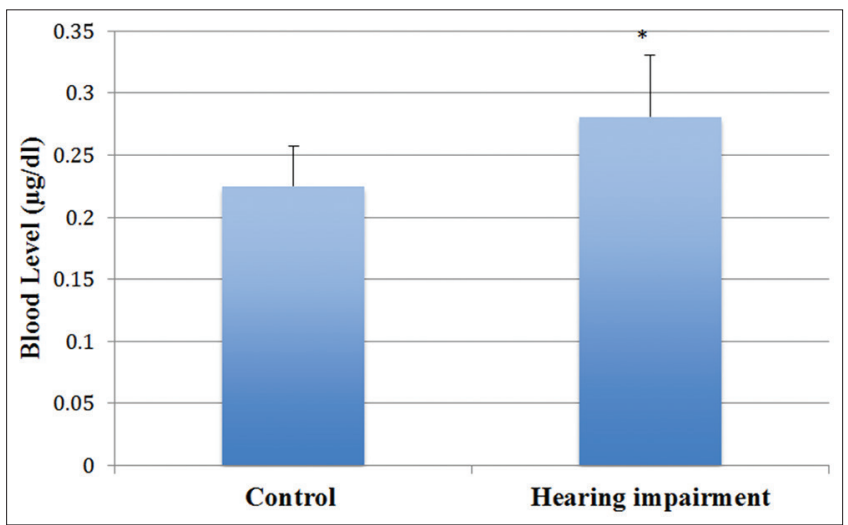

Fig. 2: Blood cadmium level in the normal people and people with hearing impairment $*$ Mean significant changes in compare to normal group $(p<0.05)$

Table 1: Serum lead level in the normal people and people with hearing impairment

\begin{tabular}{llll}
\hline Groups & $\begin{array}{l}\text { Mean blood lead level } \\
(\mu \mathbf{g} / \mathbf{d L})\end{array}$ & SD & p value \\
\hline Control & 21.20 & \pm 2.08 & 0.017 \\
Hearing impairment & $23.14^{*}$ & \pm 1.76 & \\
\hline
\end{tabular}

*Mean significant changes in compare to normal group $(\mathrm{p}<0.05)$

Table 2: Blood lead level in the normal people and people with hearing impairment

\begin{tabular}{llll}
\hline Groups & $\begin{array}{l}\text { Mean blood cadmium level } \\
(\mu \mathbf{g} / \mathbf{d L})\end{array}$ & SD & p value \\
\hline Control & 0.22 & \pm 0.03 & 0.0021 \\
Hearing & $0.28^{*}$ & \pm 0.05 & \\
impairment & & & \\
\hline
\end{tabular}

*Mean significant changes in compare to normal group $(\mathrm{p}<0.05)$ 
Many studies from humans and experimental animals obviously indicated that lead exposure could result in a negative effect on the auditory system, including electrophysiological modifications in the cochlea and hearing damage. In addition, the mechanisms underlying the lead-induced ototoxicity are mainly due to oxidative stress in mitochondria and reduced blood flow in the cochlea with consequence degeneration of inner ear receptor cells [15,24]. Furthermore, lead can also disturb the auditory brain stem [25]. The results presented in this study were harmonious with these findings. The occupational exposure to lead metal might have a role in the development of hearing impairment in some Iraqi people. In addition to this study, many previous epidemiologic reports have assessed relations between low-level lead exposure and hearing deficiencies $[17,22,26]$.

It was found that $\mathrm{Pb}$ could directly cause hearing loss with the majority of the studies, demonstrating that neurons in the cochlea and spiral ganglion neurons are more delicate than hair cells to $\mathrm{Pb}$ injury, proposing that these cells may be the major target implicated in the dedicated hearing deficits [27]. Consequently, the results of the blood lead level in this study are consistent with previous researchers that have observed neurotoxic effects from the lead at low levels.

Concerning cadmium, it is the major environmental and occupational threats that result from widespread use in manufacturing and subsequent release into the environments. The molecular mechanism of the featured harm effect of cadmium was dose and duration dependent [28].

In this study, the level of serum cadmium level in patients with hearing impairment is higher significantly by $27 \%$ in comparison to control group. This elevation in serum cadmium level may high enough to induce ototoxicity. In the USA, one study proposes that environmental exposure to low level of cadmium identified in general people could disturb hearing healthiness [17].

The current work observed that a cooperative influence of coexposure to both cadmium and lead in low levels has significantly amplified thresholds. The reasons behind that sympathetic effects are that lead and cadmium share a number of resemblances in molecular mechanisms involved in ototoxicity. Together are bivalent elements, which interfere with the protein-bound sulfhydryl group and prompt reactive oxygen species synergistically elevated through redox reactions $[29,30]$. Cadmium and lead are similarly related with alterations in the level of intracellular calcium homeostasis [31], and finally, combined exposure of lead and cadmium may result additively in auditory hair cell apoptosis and hearing impairment

Diabetes and hypertension may be possible causative intermediates as they are risk factors for auditory impairment [32,33], besides both of them are adverse consequences that may result from cadmium and lead toxicity [34-36].

An additional underlying mechanism for the revealed associations of cadmium and lead with auditory impairment is that exposures to together of them reduced bone mineral densitometry (BMD) [37,38] and disturb chronic kidney disease $[39,40]$ that consequently might have intermediary adverse outcomes on hearing impairment. This suggestion is supported by many bone disease study that has stated a relationship concerning BMD in cochlear capsule beside sensorineural auditory impairment $[41,42]$, and previous studies about the renal system that indicated an association between decreased glomerular filtration rate and neurosensory hearing impairment [43].

In fact, the current study is the first epidemiologic investigation aimed to assess relations concerning hearing impairment and lead and cadmium coexposure in Iraqi population.

\section{CONCLUSION}

The existing study revealed that the environmental and occupational cadmium and lead coexposures lead to the significant elevation in the blood level of these metals and might play an important role in the progression of hearing impairments, and the third most important disabled disorder suffered by people $\geq 65$ years of age [44]. Professionals of health hearing care should be conscious of the potential damaging adverse effects of heavy metals on the auditory structure, and a complete audiological evaluation should be considered when doubting auditory dysfunction prompted by heavy metal exposure. Our results support struggles to diminish surrounding cadmium and lead exposures to efficiently reduce hearing impairment among the overall people around the world.

\section{AUTHORS' CONTRIBUTION}

Wrood S. Al-Khfajy, Ghadeer K. Baiee, and Inam Sameh Arif contributed to the design and implementation of the research, collecting the data, analysis of the results, and to the writing of the manuscript.

\section{CONFLICTS OF INTEREST}

The authors declare no conflict of interest.

\section{REFERENCES}

1. Roth JA, Salvi R. Ototoxicity of divalent metals. Neurotoxicol Res 2016;30:268-82.

2. $\mathrm{Hu}$ H. Human health and heavy Metals. In: Life Support: The Environment and Human Health. Cambridge, USA: MIT Press; 2002. p. 65.

3. Agrawal Y, Platz EA, Niparko JK. Prevalence of hearing loss and differences by demographic characteristics among US adults: Data from the National Health and Nutrition Examination Survey, 19992004. Arch Intern Med 2008;168:1522-30.

4. World Health Organization. A Report about Deafness and Hearing Loss; 2018. Available from: http://www.who.int/mediacentre/ factsheets/fs300/en.

5. Northern JL, Down MP. Hearing Loss in Children. $5^{\text {th }}$ ed. Baltimore, MD: Williams \&Wilkins; 2002.

6. Campo P, Morata TC, Hong OS. Chemical exposure and hearing loss. Dis Mon 2013;59.4:119-38.

7. Park SK. Role of free radicals in hearing loss due to heavy metals. In: Miller J, Le Prell CG, Rybak L, editors. Free Radicals in ENT Pathology. New York: Springer International Publishing; 2015. p. 93-109.

8. Prasher D. Heavy metals and noise exposure: Health effects. Noise Health 2009; $11: 141-4$.

9. CDC, Centers for Disease Control and Prevention. Fourth National Report on Human Exposure to Environmental Chemicals: Updated Tables. Atlanta, GA: US Department of Health and Human Services, Centers for Disease Control and Prevention; 2013.

10. Mustarichie R, Indriyati W, Riokogro R. Analysis of heavy metals (lead and cadmium) contained on the illustrated ceramic plate by atomic absorption spectrophotometer. Asian J Pharm Clin Res 2017;10:125-8.

11. Prakash U, Krishnan D, Sripriya N, Bhuvaneswari S. Quality assessment for the presence of heavy metals in herbal materials from the markets of Chennai, India. Int J Pharm Pharm Sci 2014;6:574-8.

12. Institute for Health Metrics and Evaluation, IHME. GBD Compare. Seattle, WA: IHME, University of Washington; 2017.

13. United Nations Environment Programme. Leaded Petrol Phase-Out: Global Status as at March 2017. Nairobi: United Nations Environment Programme; 2017.

14. Wu XW, Ding DL, Sun H, Liu H, Jiang HY, Salvi R. Lead neurotoxicity in rat cochlear organotypic cultures. J Otol 2011;6:43-50.

15. Lasky RE, Maier MM, Snodgrass EB, Hecox KE, Laughlin NK. The effects of lead on optoacoustic emissions and auditory evoked potentials in monkeys. Neurotoxicol Teratol 1995;17:633-44.

16. Ozcaglar HU, Agirdir B, Dinc O, Turhan M, Kilinçarslan S, Oner G. Effects of cadmium on the hearing system. Act Otolaryngol 2001;121:393-7.

17. Choi YH, Hu H, Mukherjee B, Miller J, Park SK. Environmental cadmium and lead exposures and hearing loss in U.S. adults: The national health and nutrition examination survey, 1999 to 2004. Environ 
Health Perspect 2012a;120:1544-55.

18. Shargorodsky J, Curhan SG, Henderson E, Eavey R, Curhan GC. Heavy metals exposure and hearing loss in US adolescents. Arch Otolaryngol Head Neck Surg 2011;137:1183-9.

19. Al-Khfajy WS, Arif IS, Zalzala MH. Epidemiological survey of intentional and non - intentional poisoning cases in Iraq during 20142016. J Glob Pharm Technol 2017;9:189-98.

20. Choi YH, Park SK. Environmental exposures to lead, mercury, and cadmium and hearing loss in adults and adolescents: KNHANES 20102012. Environ Health Perspect 2017;125:45.

21. Informal Working Group on Prevention of Deafness and Hearing Impairment Programme Planning. Report of the Informal Working Group on Prevention of Deafness and Hearing Impairment Programed Planning. Geneva, Switzerland: World Health Organization; 1991.

22. Chuang HY, Kuo CH, Chiu YW, Ho CK, Chen CJ, Wu TN. A casecontrol study on the relationship of hearing function and blood concentrations of lead, manganese, arsenic, and selenium. Sci Total Environ 2007;387:79-85

23. Nelson DI, Nelson RY, Concha-Barrientos M, Fingerhut M. The global burden of occupational noise-induced hearing loss. Am J Ind Med 2005;48:446-58.

24. Yamamura K, Terayama K, Yamamoto N, Kohyama A, Kishi R. Effects of acute lead acetate exposure on adult guinea pigs: An electrophysiological study of the inner ear. Fundam Appl Toxicol 1989;13:509-15.

25. Jones LG, Prins J, Park S, Walton JP, Luebke AE, Lurie DI. Lead exposure during development results in increased neurofilament phosphorylation, neuritic beading, and temporal processing deficits within the murine auditory brain- stem. J Comp Neurol 2008;506:1003-17.

26. Hwang YH, Chiang HY, Yen-Jean MC, Wang JD. The association between low levels of lead in blood and occupational noise-induced hearing loss in steelworkers. Sci Total Environ 2009;408:43-9.

27. Xue-Wen W, Ding D, Hong S, Hong L, Hai-Yan J, Salvi R. Lead neurotoxicity in rat cochlear organotypic cultures. J Otol 2011;6:45-50.

28. Liu H, Ding D, Sun H, Jiang H, Wu X, Roth JA, et al. Cadmiuminduced ototoxicity in rat cochlear organotypic cultures. Neurotoxicol Res 2014;26:179-89.

29. Kapoor D, Rattan A, Kaur S, Bhardwaj R. Influence of cadmium on antioxidative defence system, photosynthesis, level of osmolytes and ions uptake in Brassica juncea. Int J Pharm Pharm Sci 2016;8:204-8.

30. Vaziri ND, Khan M. Interplay of reactive oxygen species and nitric oxide in the pathogenesis of experimental lead-induced hypertension. Clin Exp Pharmacol Physiol 2007;34:920-5.

31. Sabolic' I. Common mechanisms in nephropathy induced by toxic metals. Nephron Physiol 2006;104:107-14.
32. Bainbridge KE, Hoffman HJ, Cowie CC. Diabetes and hearing impairment in the United States: Audiometric evidence from the National Health and Nutrition Examination Survey, 1999 to 2004. Ann Intern Med 2008;149:1-10.

33. Chang TY, Liu CS, Huang KH, Chen RY, Lai JS, Bao BY. Highfrequency hearing loss, occupational noise exposure, and hypertension: A cross-sectional study in male workers. Environ Health 2011;10:35-42.

34. Hu H, Aro A, Payton M, Korrick S, Sparrow D, Weiss ST, et al. The relationship of bone and blood lead to hypertension. The normative aging study. JAMA 1996;275:1171-6.

35. Schwartz GG, Ilyasova D, Ivanova A. Urinary cadmium, impaired fasting glucose, and diabetes in the NHANES III. Diabete Care 2003;26:468-70.

36. Tellez-Plaza M, Navas-Acien A, Crainiceanu CM, Guallar E. Cadmium exposure and hypertension in the 1999-2004 National Health and Nutrition Examination Survey (NHANES). Environ Health Perspect 2008;116:51-6.

37. Alfvén T, Järup L, Elinder CG. Cadmium and lead in blood in relation to low bone mineral density and tubular proteinuria. Environ Health Perspect 2002;110:699-702.

38. Chen X, Zhu G, Jin T, Lei L, Liang Y. Bone mineral density is related with previous renal dysfunction caused by cadmium exposure. Environ Toxicol Pharmacol 2011;32:46-53.

39. Kim R, Rotnitzky A, Sparrow D, Weiss ST, Wager C, Hu H. A longitudinal study of low-level lead exposure and impairment of renal function. JAMA 1996;275:1177-81.

40. Navas-Acien A, Tellez-Plaza M, Guallar E, Muntner P, Silbergeld E, Jaar B, et al. Blood cadmium and lead and chronic kidney disease in U.S. adults: A joint analysis. Am J Epidemiol 2009;170:1156-64.

41. Güneri EA, Ada E, Ceryan K, Güneri A. High-resolution computed tomographic evaluation of the cochlear capsule in otosclerosis: Relationship between densitometry and sensorineural hearing loss. Ann Otol Rhinol Laryngol 1996;105:659-64.

42. Monsell EM, Cody DD, Bone HG, Divine GW, Windham JP, Jacobson GP, et al. Hearing loss in Paget's disease of bone: The relationship between pure-tone thresholds and mineral density of the cochlear capsule. Hear Res 1995;83:114-20.

43. Vilayur E, Gopinath B, Harris DC, Burlutsky G, McMahon CM, Mitchell P. The association between reduced GFR and hearing loss: A cross-sectional population-based study. Am J Kidney Dis 2010;56:661-9.

44. Yueh B, Shapiro N, MacLean CH, Shekelle PG. Screening and management of adult hearing loss in primary care: Scientific review. JAMA 2003;289:1976-85. 